\title{
Interleukin-1ß Induces Long-Term Potentiation of C-Fiber Evoked Field Potentials in Spinal dorsal Horn in Rats with Neuropathic Pain
}

\author{
Yi Zhong, Li-Jun Zhou, Wen-Jie Ren, Wen-jun Xin, Yong-Yong Li, Tong Zhang and \\ Xian-Guo Liu*
}

Pain Research Center and Department of Physiology, Zhongshan Medical School of Sun Yat-sen University, 510080 Guangzhou, China

\begin{abstract}
Proinflammatory cytokines, such as tumor necrosis factor-alpha (TNF- $\alpha$ ) and interleukin-1beta (IL-1 $\beta$ ), impairs long-term potentiation (LTP) in hippocampus, a synaptic model of memory, while in spinal dorsal horn TNF- $\alpha$ is found to induce LTP of C-fiber evoked field potentials in rats with nerve injury. In the present work the role of IL- $1 \beta$ in the spinal LTP of C-fiber evoked field potentials, which is important for pathological pain, was investigated in both physiological and pathological conditions. We found that spinal application of IL- $1 \beta$ at the concentrations up to $500 \mathrm{ng} / \mathrm{ml}$ affected neither basal synaptic transmission mediated by C-fiber nor spinal LTP induced by tetanic stimulation in intact rats. In rats with neuropathic pain produced by spared nerve injury (SNI) or lumbar 5 ventral root transection (L5 VRT), however, IL$1 \beta$ at a low concentration $(5 \mathrm{ng} / \mathrm{ml})$ induced LTP of C-fiber evoked field potentials. Pretreatment with either p38 MAPK inhibitor (SB203580) or NF- $\mathrm{BB}$ inhibitor (PDTC) but not with JNK inhibitor (SP600125) completely blocked LTP induced by IL-1 $\beta$ in SNI rats. Taken together, the results indicated that exogenous IL-1 $\beta$ might induce spinal LTP only in rats with nerve injury but not in intact rats. The differential effects of proinflammatory cytokines on synaptic plasticity in spinal dorsal horn and in hippocampus may be clinically significant.
\end{abstract}

Keywords: Interleukine-1, long-term potentiation, spinal dorsal horn, p38 MAPK, NK-кB, JNK.

\section{INTRODUCTION}

Long-term potentiation (LTP) of synaptic transmission, which was first observed in hippocampus [1], has been intensively studied as a synaptic model of learning and memory [2]. LTP has been demonstrated in other parts of central nervous system, such as, in spinal dorsal horn LTP of C-fiber evoked field potentials is induced not only by electrical tetanic stimulation of afferent C-fibers [3] but also by nerve injury [4]. Since C-fibers (also called pain fibers) conveys nociceptive signals to spinal dorsal horn and LTP of C-fiber evoked synaptic responses occurs primarily in the synapses between afferent C-fibers and the second order projection neurons in superficial lamina [5], the long-lasting enhancement of synaptic transmission is considered as a form of pain memory $[6,7]$. The facts that LTP-inducing stimuli produces long-lasting behavioral signs of neuropathic pain (allodynia and hyperalgesia) in human [8], as well as in animals [9] support this point of view.

Previously, many studies have demonstrated that the mechanisms underlying hippocampal LTP and spinal LTP are very similar [6]. Protein kinase C (PKC) [10], cAMPdependent protein kinase (PKA) [11], calcium/calmodulindependent protein kinase II (CaMKII) [12] are involved in LTP in both hippocampus and spinal dorsal horn [13] in the same manner. Activation of either TrkB receptor or dopamine D1/D5 receptor induces LTP in both hippocampus

\footnotetext{
*Address correspondence to this author at the Pain Research Center and Department of Physiology, Zhongshan Medical School of Sun Yat-sen University, 510080 Guangzhou, China; Tel: 0086-20-87331956;

Home: 0086-20-87333065; E-mail: liuxg@mail.sysu.edu.cn
}

$[14,15]$ and spinal dorsal horn [16, 17]. Apparently, the drugs targeting at these molecules may cure neuropathic pain but also bring on a serious side effect-memory impairment. It would be optimal to inhibit the molecules that impair hippocampal LTP but produce spinal LTP.

It has demonstrated that proinflammatory cytokines, such as TNF- $\alpha$ and IL- $1 \beta$, play important role in synaptic plasticity. Both of them inhibit LTP in CA1 and CA3 and dentate gyrus in hippocampus at pathological concentration [18-20]. The cytokines inhibit hippocampal LTP by activation of p38 MAPK [21, 22], JNK [23] and NF- $\kappa B[24]$. However, recently we have shown that spinal application of TNF- $\alpha$ does not affect spinal LTP induced by electrical stimulation in naïve animals but induces LTP in rats with nerve injury via activation of $\mathrm{p} 38$ MAPK, JNK and NF- $\mathrm{KB}$ [25]. It appears that pro-inflammatory cytokines may affect LTP in hippocampus and in spinal dorsal horn differentially. To confirm this, in the present study, the effect of IL- $1 \beta$ which produces allodynia and hyperalgesia [26-28] on spinal LTP was tested and the roles of p38 MAPK, JNK and NF- $\kappa B$ were evaluated.

\section{MATERIALS AND METHODOLOGY}

\subsection{Animals}

Experiments were performed on adult male SpragueDawley rats (200-280 g body wt). The animals were housed in separated cages and have access to food and water ad libitum. The room was kept at around $25{ }^{\circ} \mathrm{C}$ temperature and $50-60 \%$ humidity with a 12:12-h light/dark cycle. All experimental procedure was approved by the local animal care committee and was carried out in according to the 
guidelines of the National Institutes of Health on animal care and the ethical guidelines for investigation of experimental pain in conscious animals [29].

\subsection{Surgery}

\subsubsection{Spared Nerve Injury}

The procedure of spared nerve injury follows the description by [30] The rats were anesthetized with $10 \%$ chloral hydrate. The hair of the rat's left thigh was shaved, and the skin was sterilized with $0.5 \%$ chlorhexidine and covered with clean gauze. An incision was made through skin on lateral surface of the thigh and the biceps femoris muscle was dissected bluntly to expose the left sciatic nerve and its three terminal branches: the common peroneal, tibial and sural nerve. The first two were separately ligated tightly with 5-0 silk and transected distal to ligation, then 2-4 mm length of each nerve was removed. Great care was taken to avoid any contact or stretching of the sural nerve to keep it intact. The wound was washed with saline and closed in two layers.

\subsubsection{Transection of L5 Ventral root}

Rats were deeply anesthetized with sodium pentobarbital (50 $\mathrm{mg} / \mathrm{kg}$ body weight, i.p.). Additional doses of the anesthetics were given as needed. All manipulations were done on the left side of spinal column. Special care was taken to prevent infection. The hair of the rat's lower back was shaved, and the skin was sterilized with $0.5 \%$ chlorhexidine and covered with clean gauze. Sterile operating instruments were used.

The L5 VRT was done following the procedures described by Li et al. [31]. After a midline skin incision in the lumbar region, the L5 vertebra was freed of its muscular attachment. An L5 hemilaminectomy was performed, and the transverse process of the L5 vertebra was removed to expose the L5 ventral root well. The dura mater and arachnoid membrane were incised, and the L5 ventral root was identified as it lays at the most lateral side of spinal canal and just beneath the dorsal root. The ventral root was gently pulled out with fine forceps and carefully transected 2-3 mm proximal to the DRG, and a small portion (approximately $2 \mathrm{~mm}$ ) of the root was dissected. Then the wound was washed with saline and closed in layers with 3-0 silk threads. Great care was taken to avoid any damage to the nearby L5 dorsal root and its DRG.

Mechanical allodynia was assessed using von Frey hairs with the up-down method, as the description by Chaplan et al. [32]. Only the rats exhibiting significant decrease in paw withdrawal threshold after SNI or L5 VRT were selected for electrophysiological experiments.

\subsection{Electrophysiological Recording}

Anesthesia was induced and maintained with urethane $(1.5 \mathrm{~g} / \mathrm{kg}$, i.p.). Surgical level of anesthesia was verified by the stable mean arterial blood pressure and constant heart rate during noxious stimulation. The trachea was cannulated and the animal breathed spontaneously. One carotid artery was cannulated to continuously monitor the mean arterial blood pressure, which was kept from 80 to $120 \mathrm{mmHg}$. A catheter was inserted into one external jugular vein for intravenous application of saline at a rate of $0.5 \mathrm{ml} / \mathrm{h}$. A laminectomy was performed to expose the lumbar enlargement of the spinal cord, and the dura mater was incised longitudinally. The left sciatic nerve was dissected free for electrical stimulation with silver chloride hookelectrodes. The rats were placed on a stereotaxic apparatus. All exposed nerve tissues were covered with warm paraffin oil in a pool made of skin flaps, except for the spinal lumbar enlargement where a small well was formed with $4 \%$ agar, onto which drugs will be applied. Colorectal temperature was kept constantly $\left(37-38{ }^{\circ} \mathrm{C}\right)$ by a feedback-controlled heating blanket. At the end of the experiments, rats were killed with an overdose of urethane.

Electrophysiological recording of C-fiber evoked field potentials in spinal dorsal horn has been described previously [3]. Briefly, following electrical stimulation of the sciatic nerve with a bipolar silver chloride hookelectrode, field potentials were recorded at a depth of 100$500 \mu \mathrm{m}$ from the surface of the spinal cord in lumbar enlargement (L4 and L5 segments) with a tungsten microelectrode (impedance $0.5-1 \mathrm{M} \Omega$ ), which was driven by an electronically controlled microstepping motor (Narishige Scientific Instrument Laboratory) An A/D converter card (DT2821-F-16SE, Data Translation Inc.) was used to digitize and store data in a Pentium computer at a sampling rate of $10 \mathrm{kHz}$. Single square pulses $(0.5 \mathrm{~ms}$ duration, delivered every $1 \mathrm{~min}$ ) delivered to the sciatic nerve were used as test stimuli. The strength of stimulation was adjusted to 1.5-2 times of threshold for $\mathrm{C}$-fiber response. Tetanic stimulation $(40 \mathrm{~V}, 0.5 \mathrm{~ms}, 100 \mathrm{~Hz}$, given in 4 trains of $1 \mathrm{~s}$ duration at 10 s intervals) was used to induce LTP of C-fiber evoked field potentials. The distance from stimulation site at the sciatic nerve to the recording site in the lumbar spinal cord was approximately $11 \mathrm{~cm}$. Only one experiment was conducted in each animal.

\subsection{Drug Application}

Rat recombinant IL-1 $\beta$ (Calbiochem) was dissolved in $0.9 \%$ saline to a stock concentration of $100 \mathrm{ug} / \mathrm{ml}$, aliquoted in small volumes, and stored at $-80{ }^{\circ} \mathrm{C}$. The stock solution was subsequently diluted with $0.9 \%$ saline to make final concentrations immediately before administration. PDTC (Sigma) was directly dissolved in $0.9 \%$ saline to a final concentration before each experiment. SB203580 (Sigma), SP600125 (Calbiochem) and Anisomycin (Sigma) were first dissolved in DMSO to make a stock concentration of 50 $\mathrm{mM}$, and the stock solution was subsequently diluted with $0.9 \%$ saline to make final concentrations immediately before administration. Our previous study had shown that spinal application of $0.5 \%$ DMSO does not affect C-fiber evoked field potentials $[13,33]$. The drugs $(200 \mu \mathrm{l}$ in volume) were warmed before superfusion on the spinal cord surface.

\subsection{Statistical Analysis}

The amplitudes of C-fiber evoked field potentials, measured as the maximal distance from the baseline, were determined off-line by parameter extraction [17], which was implemented by DataWave (Colorado). In each experiment amplitudes of 5 consecutive field potentials recorded at 1 min intervals were averaged. The mean amplitudes of the averaged responses before drug application or tetanic stimulation served as baseline control. The summary data from different animals were expressed as means \pm SE. 
Statistical tests were carried out with SPSS 10.0 (SPSS Inc.). The data were compared using the non-parametric Wicoxon signed-rank test, and those between animals were compared using the Mann-Whitney u-test. A value of $P<0.05$ was considered significant.

\section{RESULTS}

3.1. Spinal Application of IL-1及 Does not Affect LTP of C-Fiber Evoked Field Potentials Induced by Tetanic Stimulation in Naïve Animals

In hippocampus, pretreatment with IL-1 $\beta$ at a concentration of $4 \mathrm{ng} / \mathrm{ml}$ depresses LTP induced by tetanic stimulation [23, 34]. To test whether the cytokine affects LTP of C-fiber evoked field potentials in spinal dorsal horn, IL-1 $\beta$ was applied directly onto the dorsal surface at recording segments $30 \mathrm{~min}$ after stable recording of C-fiber evoked field potentials. As show in Fig. (1), IL-1 $\beta$ at different concentrations $(5 \mathrm{ng} / \mathrm{ml}, 50 \mathrm{ng} / \mathrm{ml}$ or $500 \mathrm{ng} / \mathrm{ml}$, $200 \mu \mathrm{l}$ in volume) didn't affect LTP induced by tetanic stimulation $(40 \mathrm{~V}, 100 \mathrm{~Hz}, 0.5 \mathrm{~ms})$ delivered at $30 \mathrm{~min}$ after IL-1 $\beta$ administration.

\subsection{Spinal Application of IL-1ß Induces LTP of C-fiber Field Potentials in Rats with Nerve Injury but not in Intact Rats}

Our previous work has demonstrated that spinal application of TNF- $\alpha$ induces LTP of C-fiber evoked field potentials in rats with nerve injury but not in intact rats [25]. In the present work, we found that IL-1 $\beta$ affected spinal

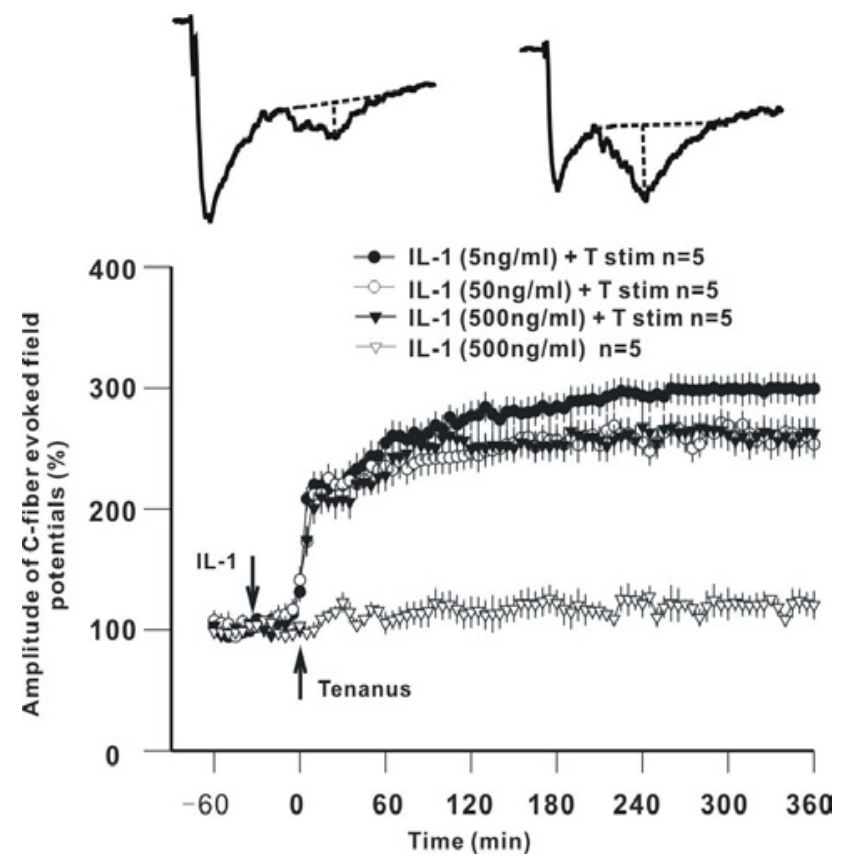

Fig. (1). IL-1及 does not affect LTP of C-fiber evoked field potentials induced by tetanic stimulation in intact rats

Mean responses of C-fiber evoked field potentials before drug application served as baseline. Data represent mean amplitudes of 5 consecutively recorded potentials. Summary data, expressed as means \pm SE, were plotted vs. time. Vertical bars indicate SEs. Downward arrows indicate the onset of drug application. Upward arrow represents the time of tetanic stimulation $(100 \mathrm{~Hz}, 40 \mathrm{~V}, 0.5$ $\mathrm{ms})$. synaptic plasticity in the same manner. As show in Fig. (2A), spinal application of IL-1 $\beta$ at a concentration as low as 5 $\mathrm{ng} / \mathrm{ml}(200 \mu \mathrm{l}$ in volume) induced LTP of C-fiber field potentials in SNI rats. At $30 \mathrm{~min}$ after IL-1 $\beta$, C-fiber evoked field potentials were potentiated significantly $(143.2 \pm 11.8 \%$, $p<0.05$, Wilcoxon signed-rank test ). At $165 \mathrm{~min}$ after IL1 Bapplication, the potentiation reached $250.8 \pm 17.5 \%$ and remained at this level until the end of the experiments (for above $6 \mathrm{~h}$ after IL-1 $\beta, \mathrm{n}=7$ ). In other five SNI rats, spinal application of saline, which was used to dissolve IL-1 $\beta$, had no effect on the $\mathrm{C}$-fiber response throughout the course of the experiment.

To confirm IL-1 $\beta$ may induce LTP in rats with nerve injury, we tested the effect of IL-1 $\beta$ on rats with L5 VRT $(n=5)$, in which motor fibers were selectively injured. Similar to the results obtained in SNI rats, C-fiber evoked field potentials were potentiated significantly $(142.6 \pm 3.73 \%$, $p<0.05$, Wilcoxon signed-rank test) at $40 \mathrm{~min}$ after IL- $1 \beta$ and reached to maximal $(220.4 \pm 9.8 \%)$ at $180 \mathrm{~min}$ after IL-1 $\beta$ (Fig. 2B).

In contrast, in intact rats, the same dosage $(5 \mathrm{ng} / \mathrm{ml}, 200$ $\mu \mathrm{l}$ in volume) of IL-1 $\beta$ had no effect on C-fiber evoked field potentials (Fig. 2C).

\subsection{Activation of p38 MAPK and NF- $\mathrm{B}$ but not JNK is Required for LTP Induced by IL-1及}

In a previous work [25] we have shown that inhibitors of p38 MAPK (SB203580), NF-кB (PDTC) and JNK (SP600125) do not affect C-fiber evoked field potentials in rats with nerve injury but completely block the spinal LTP induced by TNF- $\alpha$. In the present work we found that spinal application of both SB203580 $(100 \mu \mathrm{M})$ and PDTC (100 $\mu \mathrm{M}) 60$ min before IL-1 $\beta$ blocked the spinal LTP induced by IL-1 $\beta$ in SNI rats (Fig. 3A and B). Spinal application of SP600125 at a higher dosage $(200 \mu \mathrm{M})$, however, could only delay but not prevent the LTP induced by IL-1 $\beta$ (Fig. 3C). In the presence of the JNK inhibitor, the potentiation produced by IL-1 $\beta$ reached to significant level at $65 \mathrm{~min}$ and to maximal at $205 \mathrm{~min}$ after IL-1 $\beta$.

\subsection{Spinal LTP is Blocked by Protein Synthesis Inhibitor}

De novo protein synthesis is required for late-LTP (LLTP) but not for early-LTP (E-LTP) in both hippocampus [35] and spinal dorsal horn [36]. As our results showed exogenous IL-1 $\beta$ induced spinal LTP with a long latency, we presumed that IL-1 $\beta$ might directly induce L-LTP. To test this hypothesis, we examined whether IL-1 $\beta$ induced spinal LTP is protein synthesis-dependent. The results showed that in rats pretreated with anisomycin $(200 \mu \mathrm{M}$, in a volume of $200 \mathrm{ul}$ ), a protein synthesis inhibitor, IL-1 $\beta$ failed to produce any change in $\mathrm{C}$-fiber evoked field potentials (Fig. 4). The same dosage of anisomycin alone had no effect on baseline responses evoked by stimulation of C-fibers $[17,36]$.

\section{DISCUSSION}

\subsection{The Roles of Pro-Inflammatory Cytokines in Spinal LTP and Hippocampal LTP are Different}

It has been repetitively demonstrated that TNF- $\alpha$ [37-40] and IL-1 $\beta$ [20-22, 34, 41] at pathological concentrations inhibit LTP induced by tetanic stimulation in hippocampus. In the present study, we demonstrated that spinal application 

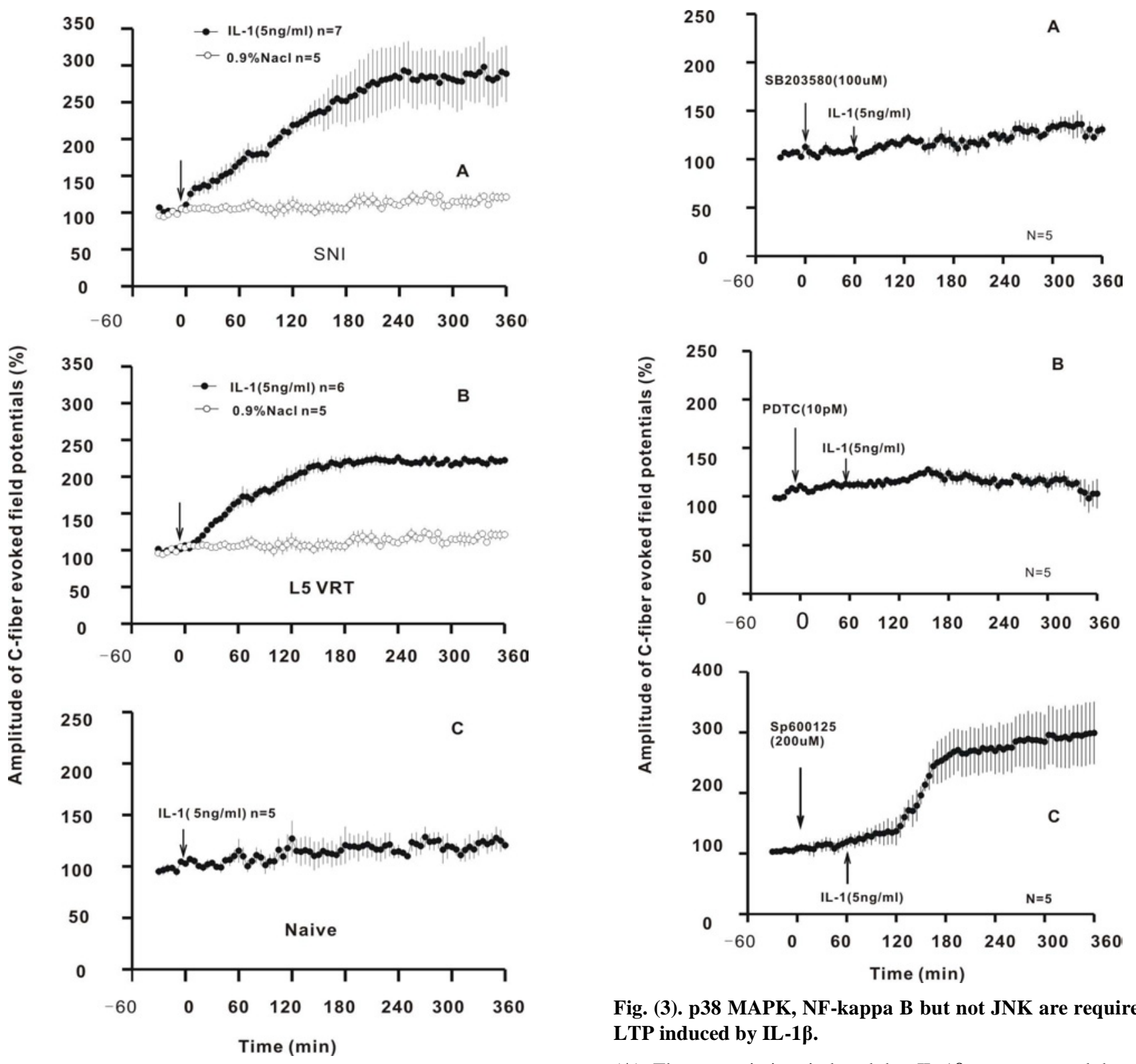

Fig. (3). p38 MAPK, NF-kappa B but not JNK are required for LTP induced by IL-1ß.

Fig. (2). IL-1 $\beta$ induces LTP of C-fiber evoked field potentials in nerve injury rats but not in intact rats

(A) Spinal application of IL-1 $\beta(5 \mathrm{ng} / \mathrm{ml}$, in $200 \mathrm{ul}$ volume, filled circles) but not saline (open circles) induced LTP of C-fiber evoked field potentials in spared nerve injury (SNI) rats. (B) The same dosage of IL-1 $\beta$ induced LTP of C-fiber evoked field potentials in lumbar 5 ventral root transection (L5 VRT) rats. (C) IL-1 $\beta$ (5 $\mathrm{ng} / \mathrm{ml}$, in 200 ul volume) had no effect on C-fiber responses in intact rats. Downward arrows indicate the onset of spinal application of IL-1 $\beta$ or saline.

of IL-1 $\beta$ affected neither basal synaptic transmission nor spinal LTP of C-fiber evoked field potentials induced by tetanic stimulation in naïve animals, but induced spinal LTP in rats with neuropathic pain produced by nerve injury (SNI or L5 VRT). The effect of IL-1 $\beta$ on synaptic plasticity in spinal dorsal horn is almost identical to that of TNF- $\alpha$ [25]. The results support our hypothesis that the effect of proinflammatory cytokines on synaptic plasticity in spinal dorsal horn is different from that in hippocampus.

(A) The potentiation induced by IL-1 1 was prevented by spinal application of p38 MAPK inhibitor SB203580 (100 uM, in $200 \mathrm{ul}$ volume) in spared nerve injury (SNI) rats. (B) Pretreatment with specific NF-kappa B inhibitor PDTC (10 pM, in $200 \mathrm{ul}$ volume) prevented LTP induced by IL-1 $\beta$. (C) Spinal application of JNK inhibitor SP600125 (200 uM, in $200 \mathrm{ul}$ volume) at $60 \mathrm{~min}$ before IL$1 \beta$ application failed to block LTP induced by IL-1 $\beta$ in SNI rats.

\subsection{The Mechanisms Underlying the Effect of Pro- Inflammatory Cytokines on Synaptic Plasticity}

It has been shown that TNF- $\alpha$ at physiological level causes an increase in surface expression of neuronal AMPA receptors, thereby increasing synaptic efficacy [41]. In IL-1 receptor 1 knockout mice hippocampal memory processes are impaired and LTP is complete absent in the dentate gyrus and in the CA1 region of hippocampus [42]. These data indicate that TNF- $\alpha$ and IL-1 are needed for memory processes and long-term synaptic plasticity in the hippocampus. However, TNF- $\alpha$ and IL-1 $\beta$ at pathological concentration inhibit LTP in hippocampus by activation of p38 MAPK [21, 22], JNK [23] and NF-אB [24]. In contrast, 


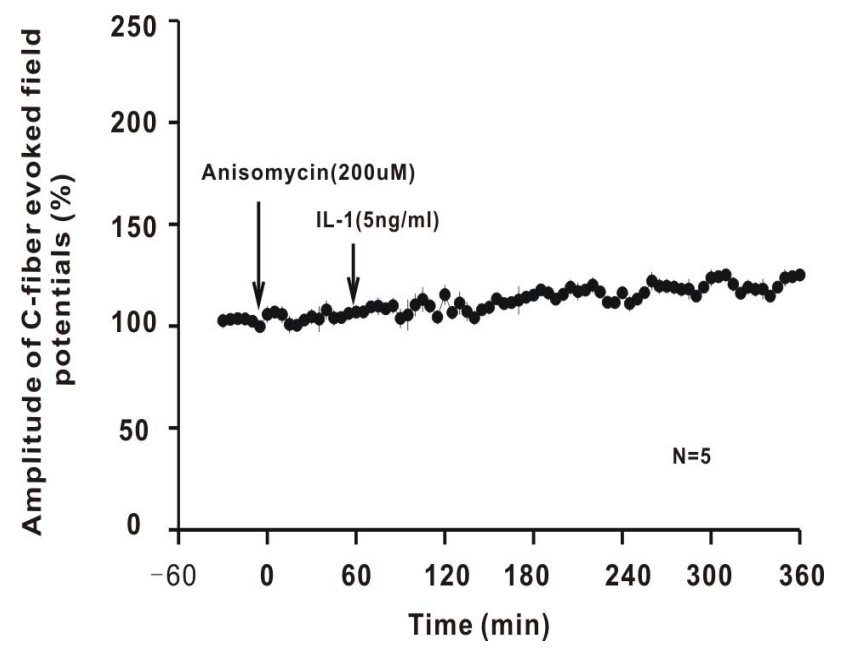

Fig. (4). Inhibition of protein synthesis prevents LTP induced by IL-1 $\beta$

Spinal application of protein synthesis inhibitor anisomycin (200 $\mu \mathrm{M}$, in $200 \mathrm{ul}$ volume) completely blocked LTP induced by IL-1 $\beta$ When applied 60 min before IL-1.

in spinal dorsal horn we found that TNF- $\alpha$ induces LTP of $\mathrm{C}$-fiber evoked field potentials in rats with nerve injury by activation of p38 MAPK, JNK and NF- $\kappa B$, while in naïve animals inhibition of p38 MAPK and JNK did not affect spinal LTP induced by electrical stimulation [25]. In the present work we further showed that spinal LTP induced by IL-1 $\beta$ was completely blocked by inhibitors of p38 MAPK and NF- $\mathrm{N}$, but not by JNK inhibitor, indicating that JNK, which is important for TNF- $\alpha$-induced LTP, may be not involved in IL-1 $\beta$-induced LTP. Furthermore, we found that IL-1 $\beta$-induced LTP was completely blocked by protein synthesis inhibitor, suggesting IL-1 $\beta$ may induce late-phase LTP, as late-phase LTP but not early-phase LTP in spinal dorsal horn is protein synthesis-dependent [36]. The findings may be significant for the treatment of neuropathic pain. The drugs targeting at pro-inflammatory cytokines and their dowmstream molecules may attenuate neuropathic pain without impairing memory in case of nerve injury.

Further studies are needed to elucidate why proinflammatory cytokines and their dowmstream molecules play different roles in hippocampus and in spinal dorsal horn in pathological conditions.

\section{ACKNOWLEDGEMENTS}

This work was supported by grants from the National Nature Science Foundation of China (No. 30700221, No.30770705) and from the National Nature Science Foundation of Guangdong (5300603).

\section{REFERENCES}

[1] Bliss TV, Lomo T. Long-lasting potentiation of synaptic transmission in the dentate area of the anaesthetized rabbit following stimulation of the perforant path. J Physiol 1973; 232: 331-56.

[2] Bliss TV, Collingridge GL. A synaptic model of memory: longterm potentiation in the hippocampus. Nature 1993; 361: 31-9.

[3] Liu XG, Sandkühler J. Long-term potentiation of C-fiber-evoked potentials in the rat spinal dorsal horn is prevented by spinal Nmethyl-D-aspartic acid receptor blockage. Neurosci Lett 1995; 191: 43-6.
[17] Zhou LJ, Zhong Y, Ren WJ, Li YY, Zhang T, Liu XG. BDNF induces late-phase LTP of C-fiber-evoked field potentials in rat spinal dorsal horn. Exp Neurol 2008; 212: 507-14.

[18] Bellinger FP, Madamba S, Siggins GR. Interleukin 1 beta inhibits synaptic strength and long-term potentiation in the rat CA1 hippocampus. Brain Res 1993; 628: 227-34.

[19] Katsuki H, Nakai S, Hirai Y, Akaji K, Kiso Y, Satoh M. Interleukin-1 beta inhibits long-term potentiation in the CA3 region of mouse hippocampal slices. Eur J Pharmacol 1990; 181: 323-6.

[20] Murray CA, Lynch MA. Evidence that increased hippocampal expression of the cytokine interleukin-1 beta is a common trigger for age- and stress-induced impairments in long-term potentiation. J Neurosci 1998; 18: 2974-81.

[21] Coogan AN, O'Neill LA, O'Connor JJ. The p38 mitogen-activated protein kinase inhibitor SB203580 antagonizes the inhibitory effects of interleukin-1beta on long-term potentiation in the rat dentate gyrus in vitro. Neuroscience 1999; 93: 57-69.

[22] Kelly A, Vereker E, Nolan Y, et al. Activation of p38 plays a pivotal role in the inhibitory effect of lipopolysaccharide and interleukin-1 beta on long term potentiation in rat dentate gyrus. J Biol Chem 2003; 278: 19453-62.

[23] Curran BP, Murray HJ, O'Connor JJ. A role for c-Jun N-terminal kinase in the inhibition of long-term potentiation by interleukin1 beta and long-term depression in the rat dentate gyrus in vitro. Neuroscience 2003; 118: 347-57.

[24] Albensi BC, Mattson MP. Evidence for the involvement of TNF and NF-kappaB in hippocampal synaptic plasticity. Synapse 2000; 35: 151-9.

[25] Liu YL, Zhou LJ, Hu NW, et al. Tumor necrosis factor-alpha induces long-term potentiation of C-fiber evoked field potentials in spinal dorsal horn in rats with nerve injury: the role of NF-kappa B, JNK and p38 MAPK. Neuropharmacology 2007; 52: 708-15. 
[26] Sommer C, Kress M. Recent findings on how proinflammatory cytokines cause pain: peripheral mechanisms in inflammatory and neuropathic hyperalgesia. Neurosci Lett 2004; 361: 184-7.

[27] Zelenka M, Schafers M, Sommer C. Intraneural injection of interleukin-1beta and tumor necrosis factor-alpha into rat sciatic nerve at physiological doses induces signs of neuropathic pain. Pain 2005; 116: 257-63.

[28] Cunha JM, Cunha FQ, Poole S, Ferreira SH. Cytokine-mediated inflammatory hyperalgesia limited by interleukin-1 receptor antagonist. Br J Pharmacol 2000; 130: 1418-24.

[29] Zimmermann M. Ethical guidelines for investigations of experimental pain in conscious animals. Pain 1983; 16: 109-10.

[30] Decosterd I, Woolf CJ. Spared nerve injury: an animal model of persistent peripheral neuropathic pain. Pain 2000; 87: 149-58.

[31] Li L, Xian CJ, Zhong JH, Zhou XF. Effect of lumbar 5 ventral root transection on pain behaviors: a novel rat model for neuropathic pain without axotomy of primary sensory neurons. Exp Neurol 2002; 175: 23-34.

[32] Chaplan SR, Bach FW, Pogrel JW, Chung JM, Yaksh TL. Quantitative assessment of tactile allodynia in the rat paw. J Neurosci Methods 1994; 53: 55-63.

[33] Xin WJ, Gong QJ, Xu JT, et al. Role of phosphorylation of ERK in induction and maintenance of LTP of the C-fiber evoked field potentials in spinal dorsal horn. J Neurosci Res 2006; 84: 934-43.

[34] Vereker E, O'Donnell E, Lynch MA. The inhibitory effect of interleukin-1beta on long-term potentiation is coupled with increased activity of stress-activated protein kinases. J Neurosci 2000; 20: 6811-9.
[35] Frey U, Krug M, Reymann KG, Matthies H. Anisomycin, an inhibitor of protein synthesis, blocks late phases of LTP phenomena in the hippocampal CA1 region in vitro. Brain Res 1988; 452: 57-65.

[36] $\mathrm{Hu} \mathrm{NW}$, Zhang HM, Hu XD, et al. Protein synthesis inhibition blocks the late-phase LTP of C-fiber evoked field potentials in rat spinal dorsal horn. J Neurophysiol 2003; 89: 2354-9.

[37] Tancredi V, D'Arcangelo G, Grassi F, et al. Tumor necrosis factor alters synaptic transmission in rat hippocampal slices. Neurosci Lett 1992; 146: 176-8.

[38] Cunningham AJ, Murray CA, O'Neill LA, Lynch MA, O'Connor JJ. Interleukin-1 beta (IL-1 beta) and tumour necrosis factor (TNF) inhibit long-term potentiation in the rat dentate gyrus in vitro. Neurosci Lett 1996; 203: 17-20.

[39] Butler MP, O'Connor JJ, Moynagh PN. Dissection of tumornecrosis factor-alpha inhibition of long-term potentiation (LTP) reveals a p38 mitogen-activated protein kinase-dependent mechanism which maps to early-but not late-phase LTP. Neuroscience 2004; 124: 319-26.

[40] Wang Q, Wu J, Rowan MJ, Anwyl R. Beta-amyloid inhibition of long-term potentiation is mediated via tumor necrosis factor. Eur $\mathbf{J}$ Neuroscience 2005; 22: 2827-32.

[41] Beattie EC, Stellwagen D, Morishita W, et al. Control of synaptic strength by glial TNF alpha. Science 2002; 295: 2282-5.

[42] Avital A, Goshen I, Kamsler A, et al. Impaired interleukin-1 signaling is associated with deficits in hippocampal memory processes and neural plasticity. Hippocampus 2003; 13: 826-34.

\section{(C) Zhong et al.; Licensee Bentham Open.}

This is an open access article licensed under the terms of the Creative Commons Attribution Non-Commercial License (http://creativecommons.org/licenses/by-nc/3.0/) which permits unrestricted, non-commercial use, distribution and reproduction in any medium, provided the work is properly cited. 